\title{
In situ DGT sensing of bioavailable metal fluxes to improve toxicity predictions for sediments
}

\author{
Minwei Xie $^{a *}$, Stuart L. Simpson ${ }^{b, c *}$, Jianyin Huang ${ }^{d}$, Peter R. Teasdale ${ }^{d}$, Wen-Xiong Wang ${ }^{e, f}$ \\ a. State Key Laboratory of Marine Environmental Science, Key Laboratory of the Ministry \\ of Education for Coastal and Wetland Ecosystem, College of the Environment and \\ Ecology, Xiamen University, Xiamen, Fujian 361102, China \\ b. Centre for Environmental Contaminants Research, CSIRO Land and Water, Sydney, \\ NSW 2234, Australia \\ c. Hong Kong Branch of Southern Marine Science and Engineering Guangdong Laboratory, \\ Guangdong, Hong Kong University of Science and Technology, Clear Water Bay, Hong \\ Kong, China \\ d. Scarce Resources and Circular Economy (ScaRCE), STEM, Future Industries Institute, \\ University of South Australia, Mawson Makes, SA 5095, Australia \\ e. School of Energy and Environment, State Key Laboratory of Marine Pollution, City \\ University of Hong Kong, Kowloon, Hong Kong, China \\ f. Research Centre for the Oceans and Human Health, City University of Hong Kong \\ Shenzhen Research Institute, Shenzhen 518057, China \\ * Corresponding authors \\ Minwei Xie: minweixie@xmu.edu.cn \\ Stuart L. Simpson: Stuart.Simpson@csiro.au
}

Number of pages: 25

Number of Tables: 4

Number of Figures: 13 
S1. Field operation, sediment collection, and laboratory sediment treatment for easily accessible locations

To assess the relationship between toxicity and DGT-metal fluxes, ten estuarine-marine locations (F1 - F6 and L1 - L4) were selected within or near Sydney, New South Wales, Australia. 41 The locations were at Five Dock Bay (FDB, F1), Kings Bay (KB, F2), Iron Cove (IC and IC-2, F3 42 and L3), Cooks River (CR, F4), Yowie Bay (YB, F5), Cockle Bay (CkB, F6), Canada Bay (CB, 43 L1), Blackwattle Bay (BWB, L2), and Port Kembla (PK, L4) (Figure S1). Among these locations, 44 six of the them $(\mathrm{F} 1-\mathrm{F} 6)$ provided easy access for sediment coring and field deployment of DGTs (shallow water depths at low tide and few hard-substrates).

At these six locations (F1 - F6), field operation and sediment collection were conducted following a nested approach (Figure S2a, b, f). At each location, three sites were selected along the shore (e.g. S1, S2, S3; Figure S2a) within a distance ranging from 100 to $1000 \mathrm{~m}$. At each site, the field operation and sediment collection were conducted in triplicates (A, B, and C; e.g. Figure $\mathrm{S} 2 \mathrm{~b}$ ) with a distance of $1 \pm 0.2 \mathrm{~m}$ apart as an equilateral triangle (Figure $\mathrm{S} 2 \mathrm{~b}, \mathrm{f}$ ). At the vertexes of the triangle, three mini-cores (Perspex cylinders, $5.5 \mathrm{~cm}$ diameter, $23 \mathrm{~cm}$ height, Figure S2 c)

52 of sediments with a depth of $\sim 4 \mathrm{~cm}$ were retrieved for toxicity tests. Besides each of the three mini53 cores, a second larger sediment core (10 cm diameter, Figure S2d, f) containing at least $10 \mathrm{~cm}-$ 54 depth of sediments were also retrieved for DGT deployment in the laboratory (Figure S2i). Care was taken to ensure minimal disturbance of the sediment water interface (SWI) within the collected cores, and also the surrounding sediments. Within $15 \mathrm{~cm}$ distance from where each pair of cores were retrieved (mini-core and larger), a deoxygenated DGT piston was inserted vertically into the sediments until the upper edge was level with the SWI (field-in-situ deployment) (Figure S2 h). These three DGT pistons (at each corner of site triangle) were each fastened with a fishing line (Figure S2g) and staked at the center of the triangle (Figure S2f) to assist with their retrieval. After a 24-h deployment, the DGT pistons were retrieved, cleaned using deionized water to remove sediments deposited on the surface, and transferred individually in clean plastic zip bag back to

64 location, an additional blank DGT was subject to the same operational procedures except 65 deployment in sediments, for quality control. Following retrieval of the DGTs, from the center of the triangle, approximately $6 \mathrm{~kg}$ of surficial sediments $(0-5 \mathrm{~cm}$ depth) were also collected using a small plastic scoop (bulk sediments that were disturbed and later homogenized in the laboratory). 
The sediments were transported back to the laboratory within $3 \mathrm{~h}$ of sediment collection.

69 The three mini-cores (toxicity test chambers) that contained sediment cores collected from the 70 field (F1 - F6) were submerged in $100 \mathrm{~L}$ seawater within the microcosm $(110 \mathrm{~L}, 52 \mathrm{~cm}$ length $\times$

$7142 \mathrm{~cm}$ width $\times 52 \mathrm{~cm}$ height, Figure S2) and seawater circulation commenced via the ports (see

72 description in the main text). The three larger sediment cores were placed into a separate 73 microcosm (110 L HDPE tank) containing 100-L of seawater and equilibrated for 9 days before 74 piston deployment (lab-equilibrated deployment). The bulk surface sediments collected from the 75 center of the triangle was homogenized in laboratory and transferred into three 500-mL plastic 76 beakers (triplicates). These three beakers containing homogenized sediments were then placed into 77 the same microcosm containing the larger sediment cores, and equilibrated for an additional $48 \mathrm{~h}$ 78 before DGTs were deployed (lab-homogenized deployment). The lab-equilibrated and lab79 homogenized deployments were arranged that DGT pistons were inserted and retrieved 80 simultaneously. Right before the deployment of DGT pistons, seawater in the microcosm was 81 emptied, deoxygenated DGTs were inserted vertically into the sediment until their upper edges 82 levelling at the sediment water interface (Figure S2i), and clean seawater was then filled. These 83 DGT pistons were also deployed for $24 \mathrm{~h}$, retrieved, cleaned and stored as described above. A 84 blank DGT piston was also prepared following the same operational procedures except deployed 85 into sediments. To ensure enough mixing in the overlying water during sediment stabilization and 86 DGT deployment, a peristaltic pump circulated the seawater at a flow rate of $240 \mathrm{~mL} / \mathrm{min}$ by taking 87 it from the top and pumping it back to the microcosm through branched tubing (Figure S2i).

88 From this design, we are able to assess the performance in predicting metal toxicity for the 89 relatively undisturbed locations F1 - F6 using DGT flux measurements from three deployment 90 scenarios: field-in-situ, lab-equilibrated, and lab-homogenized. 

deployment for less accessible locations

The sites at all these locations had beds of rock oysters, shell debris and rock that prevented collection of cores and DGT piston deployment in a nested design. At the four less accessible

97 locations where in situ coring and field operations for DGT were not feasible, only bulk surficial sediments (0-5 cm depth) were collected. Three (L1 and L3) to four (L2) sites along the shore were selected, and sediments were collected using a shovel. At location L4, a single site was selected due to deep water depth $(>5 \mathrm{~m})$ and sediments was collected with a grab sampler.

Upon return to the laboratory, these bulk sediments were press-sieved through a 2-mm plastic mesh to remove larger debris (rock and shells). Sieved sediments were then mixed with seawater (salinity 30, volume ratio of sediment: seawater $=1: 2)$ in a large tray $(\sim 70 \mathrm{~cm} \times 40 \mathrm{~cm} \times$ 20-cm depth), where they were homogenized into suspension slurry 3 to 4 times daily for a week. During this week, air was continuously bubbled to keep the slurry oxygenated. After the oxidation week, sediments were settled for a few hours, overlying water decanted, and deposited sediment transferred into a rectangular plastic container $(27 \times 18 \times 17 \mathrm{~cm})($ Figure 1). The plastic container was then placed into the microcosm, where seawater was filled and sediment inside was equilibrated for a duration of 4 weeks. During this equilibration period, to keep the overlying water at a turbulent and oxygenated state, the water was continuously circulated through a peristaltic pump and was renewed once a week.

At the end of the 4-week equilibration, seawater in the microcosm was removed and discarded, and three deoxygenated DGT pistons were inserted into sediments at each plastic container ( $\sim 5 \mathrm{~cm}$ away from container walls and at least $15 \mathrm{~cm}$ apart) as replicates to measure metal fluxes (lab-equilibrated deployment) (Figure 1). Besides the DGT pistons, sediment minicores were also obtained for toxicity test (Figure 1). To minimize disturbance of the sediment

117 structure, those mini-cores were inserted into sediment bed right before DGT pistons were 118 retrieved.

Following retrieval of DGT pistons and sediment mini-cores, the residual sediments were

120 re-homogenized within the same plastic boxes, and stabilized under the same conditions for an 121 additional $48 \mathrm{~h}$. The stabilization was terminated by deploying another three deoxygenated pistons 122 to measure metal fluxes in the re-homogenized sediments (lab-homogenized deployment). Blank 
123 DGT pistons were also prepared for both deployment events following the same procedures as 124 described above.

From this design, we are able to assess the performance in predicting metal toxicity for the highly-disturbed sediment from locations L1 - L4 using DGT flux measurements from two deployment scenarios: lab-equilibrated and lab-homogenized.

\section{S3. Collection of control sediments and seawater}

For laboratory toxicity tests, clean sediment was collected from an intertidal site at Bonnet Bay, Sydney, Australia. This fine-grained sediment $(90 \%$ of particles with diameter < $180 \mu \mathrm{m}$ ) was routinely used to culture the amphipod Melita plumulosa in the laboratory and also frequently used as control sediments in prior studies. ${ }^{1-3}$ Before using as control sediment in the present study, the sediment was mixed with clean Sydney sand (0.6-1.5 $\mathrm{mm}$ in diameter) to a ratio of $50 \%$ by weight, as a representative size distribution $(\sim 45 \%$ of particles with diameter $<$ $180 \mu \mathrm{m}$, Table S1) of all sediments tested.

Seawater (salinity $~ 35)$ was collected from Cronulla, Sydney, filtered $(0.45 \mu \mathrm{m})$, adjusted to a salinity of 30 by adding reverse-osmosis purified (RO) water, and stored in a temperaturecontrolled room $\left(21 \pm 1^{\circ} \mathrm{C}\right)$.

\section{S4. Toxicity test procedures}

The 10-day toxicity tests commenced with the introduction of twelve adult amphipods (6 gravid female and 6 male) into each exposure chamber (Day 0). Over the 10-day exposure, $50 \mathrm{~L}$ of seawater in the microcosm was replaced twice, on day 3 and 7. Following filling of seawater, amphipods were fed three times with Sera Micron fish food (1 mg/individual) on day 0, 3 and 7. On day 10 at test completion, exposure chambers were disassembled, surficial sediments $(<0.5$

152 Rose Bengal solution $(50 \mathrm{mg} / \mathrm{L})$ and the population was counted. ${ }^{4}$

\section{S5. General methods, sampling and chemical analysis}


All chemicals were of AR grade or equivalent purity. Plasticwares used to collect or

157 contain sediments were thoroughly washed with detergent and rinsed twice with RO water. Other plastic containers in direct contact with experimental reagents were cleaned by soaking into $10 \%$ $\mathrm{HNO}_{3}$ for at least $24 \mathrm{~h}$ followed by rinsing twice with deionized water (18.2 M $2 . \mathrm{cm}$, Milli-Q,

160 Millipore).

\section{S5.1 Water samples}

Metal concentrations in the overlying seawater provide an estimate of waterborne metal exposure that may contribute to toxicity. Seawater samples $(10 \mathrm{~mL})$ were collected from the holding tanks at the commencement and completion, as well as before and after the water renewal. Water samples were filtered $(0.4 \mu \mathrm{m})$, discarding the first $4 \mathrm{~mL}$ and retaining the next 6 $\mathrm{mL}$, and then acidified with nitric acid to a $\mathrm{pH}<2$ and stored at $4^{\circ} \mathrm{C}$. Not all of these samples were analyzed, but only those from tests with a reproduction outcome $<90 \%$ of controls. The analysis of metals in waters and acid digests were performed using inductively coupled plasmaatomic emission spectrometry (ICP-AES, Varian 730-ES) following the same QA/QC procedures described in Zhang et al. ${ }^{3}$ The time-averaged metal concentrations in the overlying

$172 \mathrm{Cd}, \mathrm{Cu}, \mathrm{Ni}$, and $\mathrm{Zn}$, and $5 \mu \mathrm{g} / \mathrm{L}$ for $\mathrm{Pb}$ in seawater.

\section{S5.2 Sediment samples}

Bulk sediment samples were used to characterize sediment properties, including size

176 SEM), total recoverable metal concentrations (TRM), total organic carbon (TOC) and total

177 polycyclic aromatic hydrocarbons $(\mathrm{PAH})$. The fine fraction of sediments $(<180 \mu \mathrm{m})$ was

178 determined by wet-sieving sediments at $180 \mu \mathrm{m}$, followed by measuring the dry weight. AVS

179 was determined following a rapid extraction method. ${ }^{5}$ AEM was extracted by digestion of wet-

180 sediment in 1-M HCl for $60 \mathrm{~min}{ }^{4}$ TRM was extracted by low-pressure microwave facilitated

181 (MARS 5, CEM) digestion using aqua regia. ${ }^{6}$ Metals in acid digest were measured by

182 inductively coupled plasma atomic emission spectrometry (ICP-AES, Varian 730-ES). TOC and

183 PAH were analyzed by National Measurement Institute (NMI, Sydney, Australia), a laboratory

184 accredited by the National Association of Testing Authorities (NATA), following methods as

185 described in Remaili et al. ${ }^{7}$ 
S5.3 QA/QC for analysis of metals in acid extractions from DGT piston samples using ICP-MS

All acid-extracts from DGT piston samples were analyzed using ICP-MS (8800 Triple Quad, Agilent Technologies). Quality control procedures were applied and included using internal 190 reference standards, running regular blank samples, measuring quality control standards of $100 \mu \mathrm{g}$ 191 L $^{-1}$ (High-purity standards ICP-200.8-1) for every 20 samples, measuring the samples in duplicate 192 randomly, and using CRM (SRM 1643e from National Institute of Standards and Technology), a 193 certified freshwater sample for trace metal. Samples were re-analysed if these measures indicated 194 a problem. Recoveries for QC were between $97 \%$ and 114\% for all measured metals. Recoveries 195 for samples and CRM were between $87 \%$ and $118 \%$, and between $87 \%$ and $118 \%$ respectively, 196 cross different metals.

Table S1. Recoveries for QC, samples and CRM cross different metals.

\begin{tabular}{lllll}
\hline Metal & Recovery of QC $(\%)$ & $\begin{array}{l}\text { Recoveries of } \\
\text { samples }(\%)\end{array}$ & $\begin{array}{l}\text { Recoveries of } \\
\text { CRM }\end{array}$ & $\begin{array}{l}\text { Metal concentration in } \\
\text { CRM }(\mu \mathrm{g} / \mathrm{L})\end{array}$ \\
\hline $\mathrm{Mn}$ & $114.7 \pm 2.0$ & $100.4 \pm 1.0$ & $91.9 \pm 5.4$ & $39.0 \pm 1.4$ \\
$\mathrm{Fe}$ & $105.0 \pm 2.3$ & $100.6 \pm 1.4$ & $98.1 \pm 3.7$ & $98.1 \pm 0.5$ \\
$\mathrm{Co}$ & $109.5 \pm 1.9$ & $91.7 \pm 8.4$ & $100.6 \pm 4.3$ & $27.1 \pm 0.3$ \\
$\mathrm{Ni}$ & $101.4 \pm 2.0$ & $100.6 \pm 9.7$ & $97.8 \pm 1.2$ & $62.4 \pm 0.7$ \\
$\mathrm{Cu}$ & $97.2 \pm 2.1$ & $118 \pm 5.6$ & $118.9 \pm 7.5$ & $22.8 \pm 0.3$ \\
$\mathrm{Zn}$ & $99.3 \pm 1.5$ & $101.3 \pm 1.2$ & $87.6 \pm 3.3$ & $78.5 \pm 2.2$ \\
$\mathrm{Cd}$ & $103.4 \pm 1.8$ & $87.6 \pm 7.5$ & $87.0 \pm 4.5$ & $6.6 \pm 0.07$ \\
$\mathrm{~Pb}$ & $104.5 \pm 3.2$ & $96.6 \pm 4.0$ & $90.7 \pm 5.6$ & $19.6 \pm 0.2$ \\
\hline
\end{tabular}


Table S2. Physical and chemical properties of sediments from different sites.

\begin{tabular}{|c|c|c|c|c|c|c|c|c|c|c|c|}
\hline & & & & $\begin{array}{r}\text { Total reco } \\
(\mathrm{m}\end{array}$ & $\begin{array}{l}\text { able meta } \\
\text { dry weig }\end{array}$ & TRM) & & Total PAHs & AVS & TOC & $\begin{array}{c}\text { Size } \\
<180 \mu \mathrm{m}\end{array}$ \\
\hline & & & $\mathrm{Cu}$ & $\mathrm{Zn}$ & $\mathrm{Ni}$ & $\mathrm{Pb}$ & $\mathrm{Cd}$ & & $\mathrm{O} / \mathrm{g})$ & & \\
\hline & F1 S1 & FDB S1 & $45 \pm 17$ & $500 \pm 180$ & $4.9 \pm 1.5$ & $83 \pm 31$ & $0.19 \pm 0.15$ & & $<0.5$ & 1.0 & 21 \\
\hline & F1 S2 & FDB S2 & $31 \pm 1$ & $540 \pm 80$ & $6.9 \pm 1.1$ & $61 \pm 8$ & $0.26 \pm 0.15$ & 2.6 & $<0.5$ & 1.6 & 7.4 \\
\hline & F1 S3 & FDB S3 & $62 \pm 1$ & $340 \pm 40$ & $5.8 \pm 0.6$ & $100 \pm 20$ & $0.48 \pm 0.09$ & & $<0.5$ & 1.9 & 27 \\
\hline & F2 S1 & KB S1 & $120 \pm 40$ & $510 \pm 210$ & $11 \pm 2$ & $170 \pm 60$ & $0.73 \pm 0.37$ & & $1.9 \pm 0.3$ & 3.3 & 19 \\
\hline & F2 S2 & KB S2 & $310 \pm 60$ & $1100 \pm 300$ & $17 \pm 4$ & $370 \pm 70$ & $2.0 \pm 0.6$ & 24 & $90 \pm 22$ & 14 & 61 \\
\hline 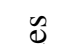 & F2 S3 & KB S3 & $73 \pm 46$ & $140 \pm 10$ & $8.4 \pm 0.9$ & $56 \pm 6$ & $0.95 \pm 0.05$ & & $1.4 \pm 0.6$ & 0.6 & 6.2 \\
\hline s: & F3 S1 & IC S1 & 230 & 1600 & 13 & 315 & 1.5 & & $4.8 \pm 1.7$ & 2.2 & 33 \\
\hline$\frac{0}{0}$ & F3 S2 & IC S2 & 310 & 1700 & 24 & 575 & 3.3 & 39 & $27 \pm 3$ & 7.7 & 58 \\
\hline 营 & F3 S3 & IC S3 & 90 & 460 & 11 & 194 & 1.6 & & $27 \pm 4$ & 3.1 & 50 \\
\hline 8 & F4 S1 & CR S1 & $100 \pm 20$ & $280 \pm 30$ & $24 \pm 13$ & $210 \pm 60$ & $0.49 \pm 0.16$ & & $<0.5$ & 1.4 & 10 \\
\hline$\pi$ & $\mathrm{F} 4 \mathrm{~S} 2$ & CR S2 & $160 \pm 20$ & $960 \pm 120$ & $21 \pm 2$ & $300 \pm 30$ & $2.5 \pm 0.3$ & 17 & $10 \pm 3$ & 8.9 & 66 \\
\hline 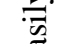 & F4 S3 & CR S3 & $58 \pm 17$ & $250 \pm 90$ & $7.9 \pm 3.4$ & $110 \pm 30$ & $0.81 \pm 0.12$ & & $<0.5$ & 2.2 & 18 \\
\hline エึ & F5 S1 & YB S1 & $28 \pm 11$ & $110 \pm 40$ & $2.9 \pm 1.6$ & $35 \pm 14$ & $0.59 \pm 0.44$ & & $4.1 \pm 3.6$ & 2.4 & 23 \\
\hline & F5 S2 & YB S2 & $12 \pm 4$ & $48 \pm 13$ & $1.7 \pm 0.6$ & $29 \pm 8$ & $0 \pm 0$ & 4.0 & $<0.5$ & 0.6 & 21 \\
\hline & F5 S3 & YB S3 & $30 \pm 9$ & $35 \pm 2$ & $2.4 \pm 2.3$ & $49 \pm 18$ & $0 \pm 0$ & & $0.7 \pm 0.7$ & 1.9 & 42 \\
\hline & F6 S1 & CkB S1 & $61 \pm 1$ & $1300 \pm 0$ & $6.9 \pm 0.1$ & $330 \pm 10$ & $52 \pm 3$ & & $12 \pm 6$ & 5.7 & 98 \\
\hline & F6 S2 & CkB S2 & $57 \pm 0$ & $1300 \pm 0$ & $7.2 \pm 0.8$ & $340 \pm 10$ & $56 \pm 3$ & 3.5 & $8.8 \pm 2.0$ & 5.2 & 99 \\
\hline & F6 S3 & CkB S3 & $60 \pm 1$ & $1300 \pm 0$ & $7.9 \pm 1.0$ & $350 \pm 10$ & $57 \pm 2$ & & $13 \pm 11$ & 4.7 & 98 \\
\hline & L1 S1 & CB S1 & $920 \pm 30$ & $420 \pm 30$ & $9.4 \pm 1.8$ & $140 \pm 0$ & $0.20 \pm 0.09$ & & $3.9 \pm 0.2$ & 2.2 & 22 \\
\hline & L1 S2 & CB S2 & $1300 \pm 00$ & $450 \pm 20$ & $9.8 \pm 0.7$ & $160 \pm 10$ & $0.59 \pm 0.12$ & 4.6 & $1.2 \pm 0.7$ & 3.6 & 23 \\
\hline & L1 S3 & CB S3 & $470 \pm 20$ & $510 \pm 10$ & $11 \pm 1$ & $220 \pm 10$ & $0.69 \pm 0.22$ & & $46 \pm 8$ & 5.9 & 36 \\
\hline. & L2 S1 & BWB S1 & $450 \pm 10$ & $1300 \pm 0$ & $19 \pm 3$ & $450 \pm 20$ & $0.74 \pm 0.23$ & & $11 \pm 7$ & 4.8 & 31 \\
\hline$\stackrel{\infty}{0}$ & L2 S2 & BWB S2 & $370 \pm 0$ & $1100 \pm 0$ & $25 \pm 1$ & $540 \pm 10$ & $1.4 \pm 0.4$ & & $140 \pm 20$ & 15 & 17 \\
\hline $\overrightarrow{0}$ & L2 S3 & BWB S3 & $310 \pm 20$ & $960 \pm 60$ & $22 \pm 1$ & $470 \pm 30$ & $1.1 \pm 0.2$ & 11 & $61 \pm 8$ & 11 & 27 \\
\hline 8 & L2 S4 & BWB S4 & $380 \pm 10$ & $1200 \pm 0$ & $35 \pm 2$ & $580 \pm 10$ & $1.3 \pm 0.2$ & & $41 \pm 5$ & 11 & 45 \\
\hline$\underset{\mathscr{J}}{\Xi}$ & L3 S1 & IC-2 S1 & $220 \pm 10$ & $920 \pm 20$ & $14 \pm 0$ & $400 \pm 40$ & $1.9 \pm 0.4$ & & $4.8 \pm 1.7$ & 4.7 & 39 \\
\hline & L3 S2 & IC-2 S2 & $340 \pm 10$ & $1900 \pm 100$ & $23 \pm 1$ & $570 \pm 20$ & $2.8 \pm 0.4$ & 14 & $27 \pm 3$ & 6.6 & 46 \\
\hline & L3 S3 & IC-2 S3 & $180 \pm 0$ & $760 \pm 10$ & $16 \pm 1$ & $360 \pm 10$ & $2.1 \pm 0.2$ & & $27 \pm 4$ & 6.0 & 63 \\
\hline & L4 S1 & PK S1 & $560 \pm 80$ & $620 \pm 0$ & $11 \pm 1$ & $290 \pm 0$ & $0.89 \pm 0.20$ & 5.5 & $0.5 \pm 0.0$ & 2.6 & 45 \\
\hline
\end{tabular}

$206 \mathrm{TRM}=$ total recoverable metal concentration, $\mathrm{AVS}=$ acid-volatile sulfide, $\mathrm{TOC}=$ total organic carbon, $\mathrm{PAH}=$ total polycyclic aromatic

207 hydrocarbons (sum of 16 individual PAHs), Size = particle size. 
208 Table S3. Derived effect concentrations (EC values) under different deployed scenarios.

209 DGT $_{\mathrm{TU}}$ (sum of individual metals after normalizing DGT fluxes to water quality guidelines)

\begin{tabular}{clrrr} 
& \multirow{2}{*}{ Deployment scenario } & \multicolumn{3}{c}{ Effect concentrations } \\
\cline { 3 - 5 } & & EC10 & EC20 & EC50 \\
\hline \multirow{2}{*}{$\begin{array}{c}\text { Easily accessible } \\
\text { sites }\end{array}$} & DGT in-situ & $11(5.7-15)$ & $22(14-27)$ & $66(44-67)$ \\
& DGT lab-equilibrated & $12(6.2-35)$ & $18(18-49)$ & $36(18-48)$ \\
& DGT lab-homogenized & $6.9(\mathrm{NA}-29)$ & $12(3-48)$ & $33(20-60)$ \\
& & & \\
Inaccessible sites & DGT lab-equilibrated & $1.9(\mathrm{NA})$ & $5.8(\mathrm{NA})$ & $38(\mathrm{NA})$ \\
& DGT lab-homogenized & $3.0(\mathrm{NA})$ & $4.9(\mathrm{NA})$ & $11(\mathrm{NA})$ \\
Amato's beaker & & & \\
study & Homogenized sed. & $14(8-27)$ & $17(11-28)$ & $25(10-32)$ \\
\hline
\end{tabular}

NA means not available

Table S4. EC20 values as DGTTU for individual metals under different deployment scenarios.

\begin{tabular}{clrrr}
\hline & \multirow{2}{*}{ Deployment scenario } & \multicolumn{3}{c}{ EC20 (DGTTU) } \\
\cline { 3 - 5 } Easily accessible & DGT in-situ & $6.0(3.1-8.1)$ & $15(7.8-20)$ & $1.5(1.3-1.7)$ \\
sites & DGT lab-equilibrated & 14 (NA-NA) & $20(0.6-34)$ & - \\
& DGT lab-homogenized & 5.5 (NA-NA) & $9.0(1.5-25)$ & - \\
& & & - \\
\multirow{2}{*}{ Inaccessible sites } & DGT lab-equilibrated & 3.9 (NA-5.6) & - & - \\
& DGT lab-homogenized & $3.1($ NA-25) & - & - \\
\hline
\end{tabular}

NA means not available 


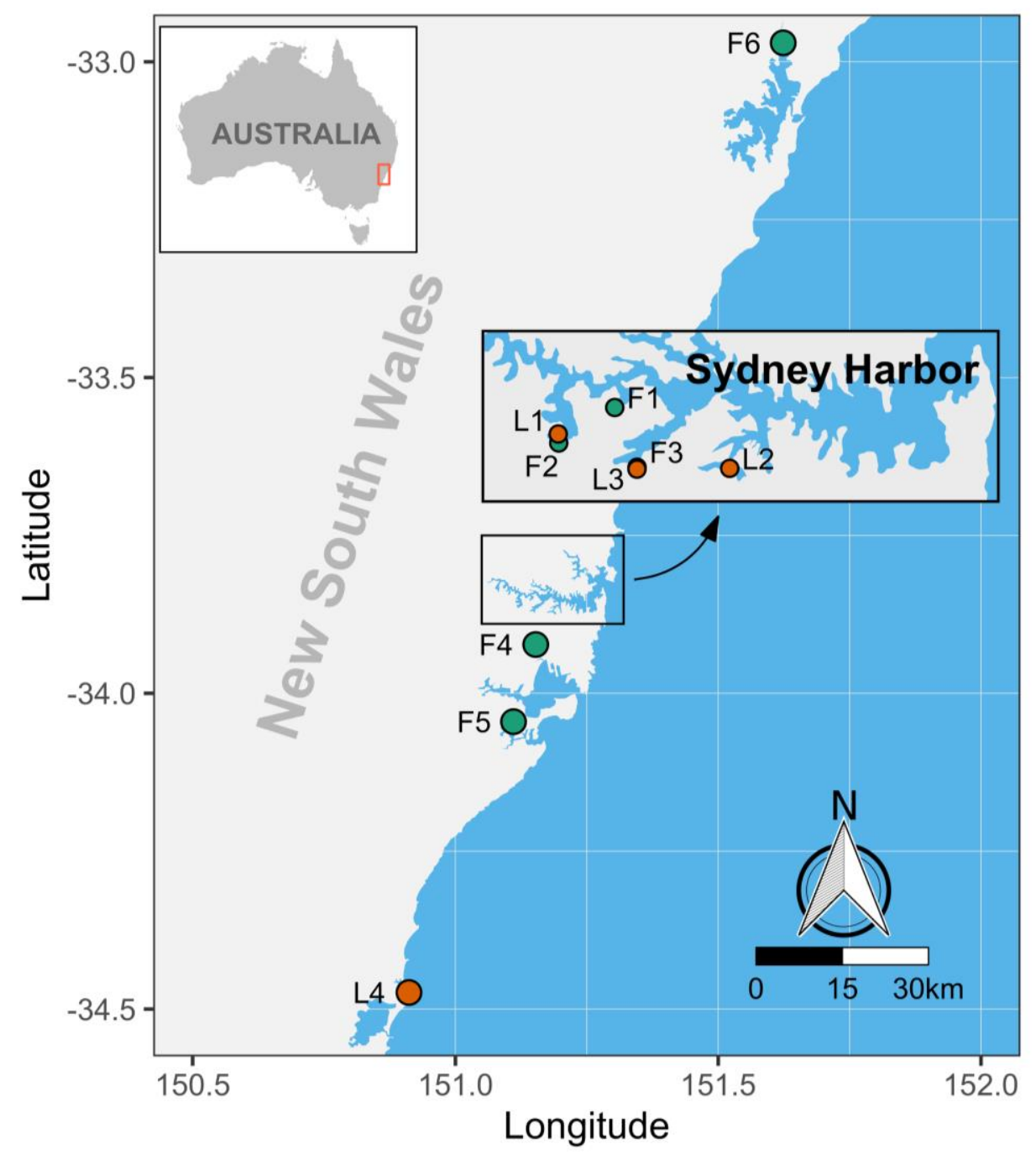

220 Figure S1. Sampling locations along the coast of New South Wales. Green points indicate 221 easily accessible sites (F1 - F6) where field operation and sediment coring were conducted; 222 red points indicate inaccessible sites $(\mathrm{L1}-\mathrm{L} 4)$ where bulk sediments were collected. 


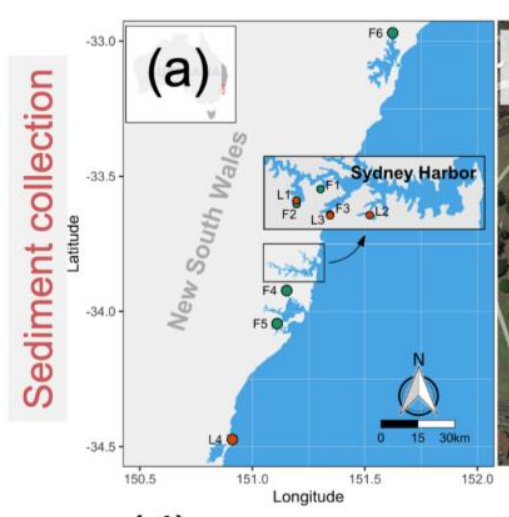

(d)

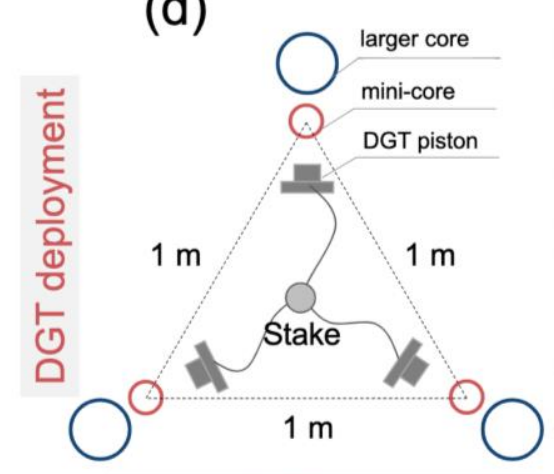

In-situ DGT deployment

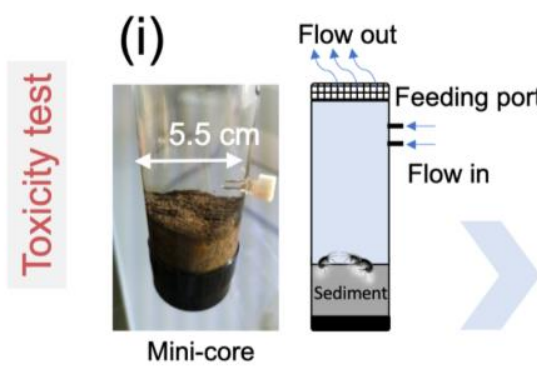

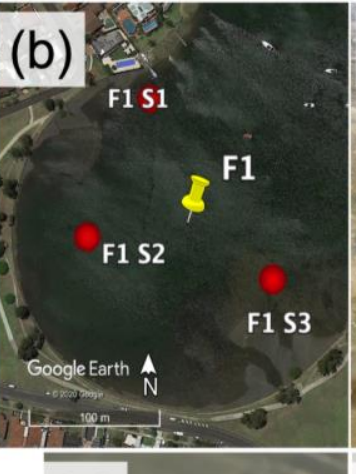

(e)
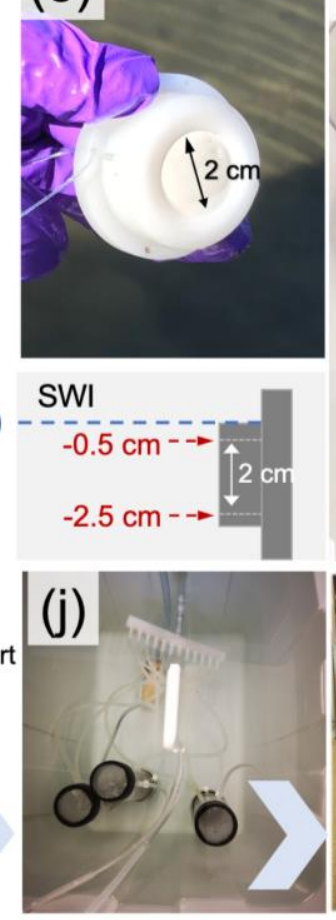
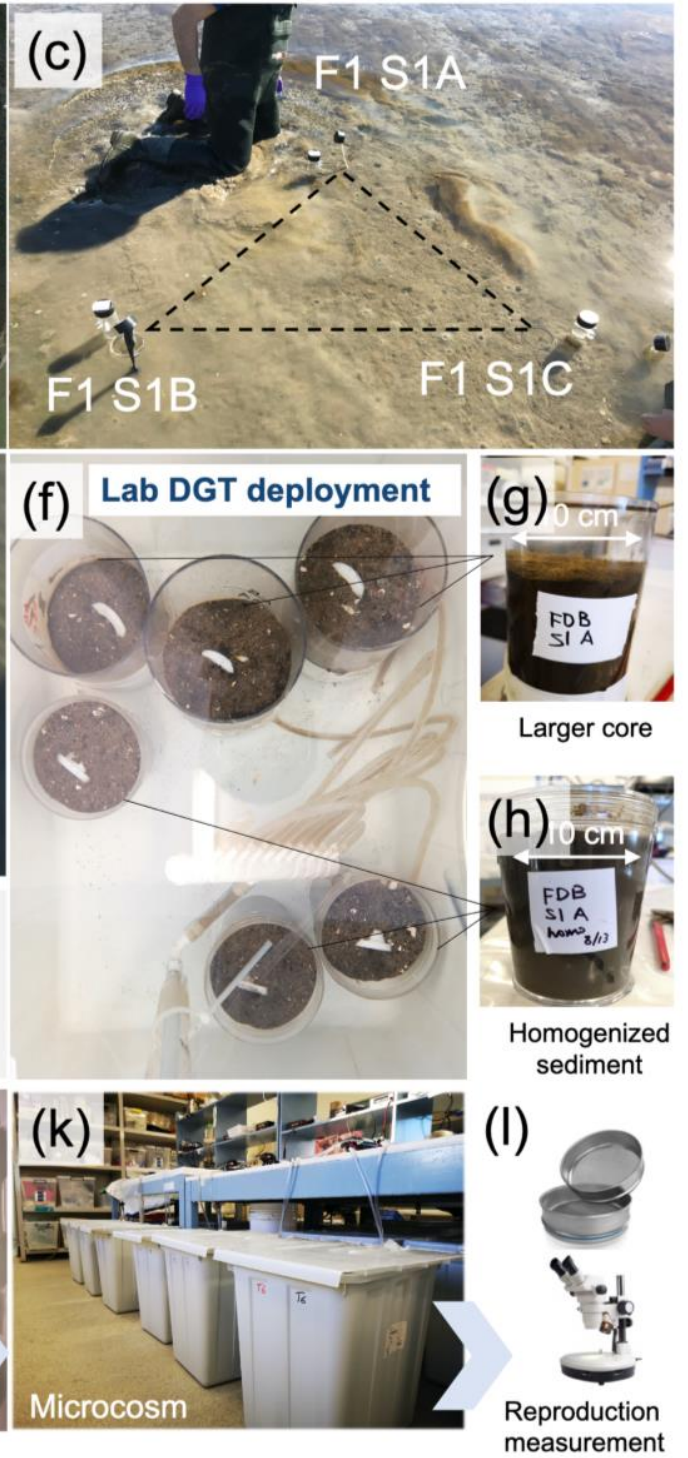

Figure S2. Field operation for easily accessible sites and toxicity test setup. (a) Sampling

227 locations along the coast of New South Wales; (b) Three sites around $100 \mathrm{~m}$ apart were selected along the shoreline at location F1; (c) At each site (F1 here), field operations (sediment coring and DGT piston deployments) were conducted in triplicates (A, B, C) with a distance of $1 \pm 0.2$ m apart; (d) Layout for field deployment of DGT pistons and collection of sediment cores; (e)

231 DGT pistons were fastened with fishing lines, vertically inserted into sediments, and staked at the center to ease retrieval; (f) Deployment of DGT pistons in larger cores and homogenized sediments in a laboratory microcosm; $(\mathrm{g}, \mathrm{h})$ a larger core for DGT piston deployment in the lab (DGT lab-equilibrated scenario), and a beaker with homogenized sediment for DGT piston deployment (DGT lab-homogenized scenario); (i-1) Toxicity of sediments to amphipod was measured in a semi-flow-through chamber within the laboratory microcosm, and reproduction was determined as an endpoint. 


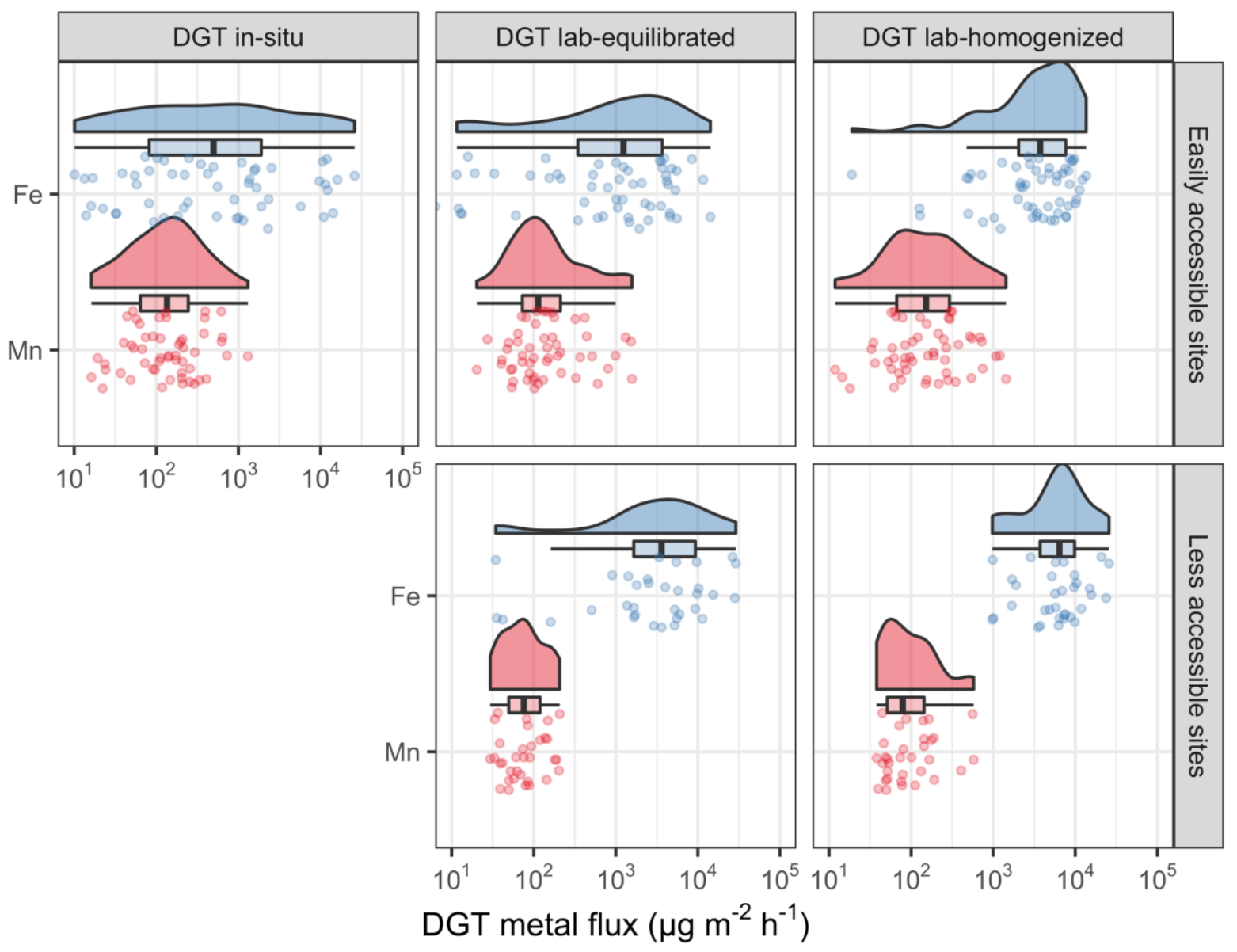

239 Figure S3. Distribution of DGT labile metal fluxes for Fe and Mn. DGT Fe fluxes increased 240 with the level of disturbance. Each raincloud plot combines a probability density function of 241 metal fluxes, a boxplot providing statistical inferences, and scattered data points of normalized 242 metal fluxes. 

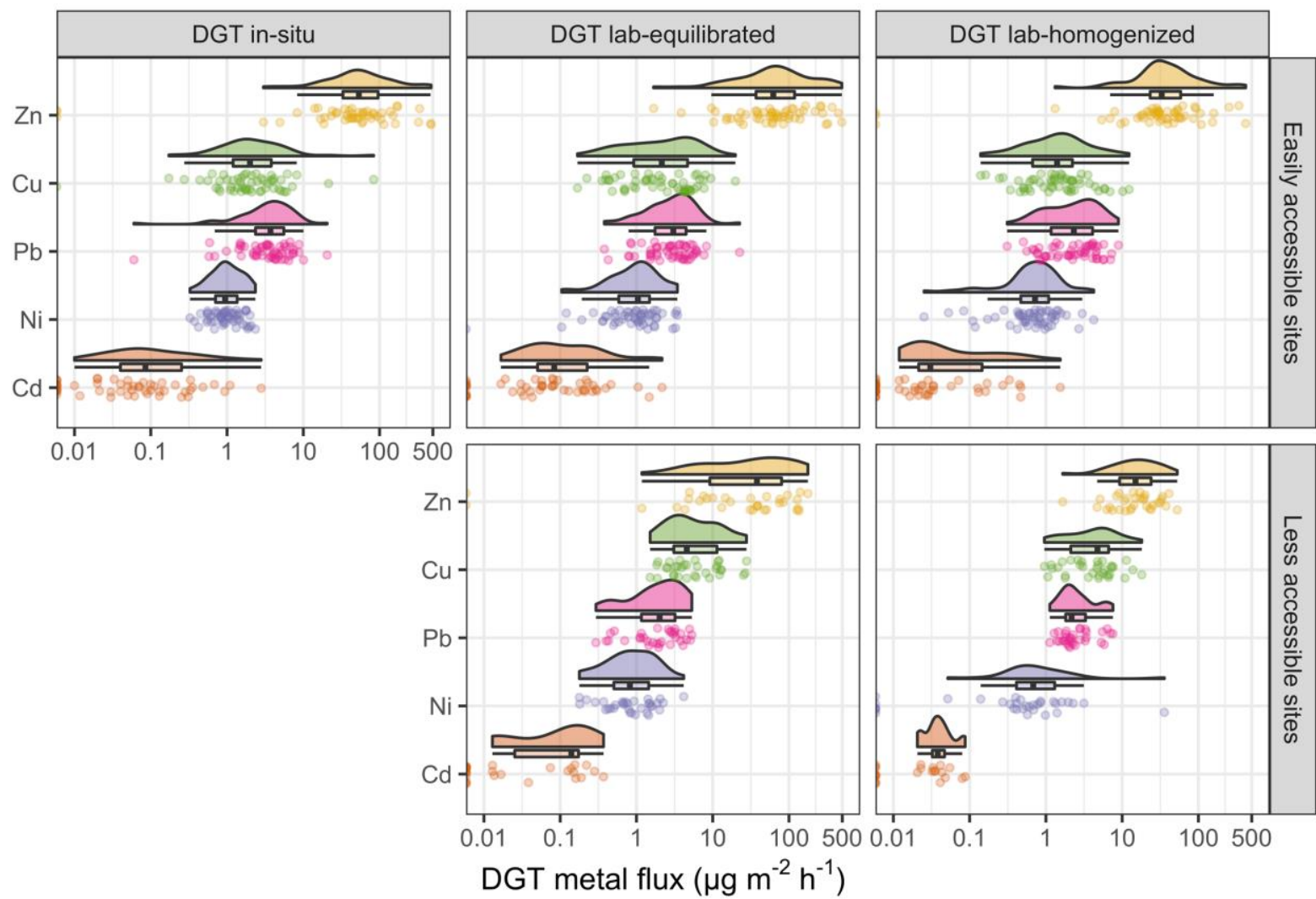

DGT metal flux $\left(\mu \mathrm{g} \mathrm{m}^{-2} \mathrm{~h}^{-1}\right)$

244 Figure S4. Distribution of DGT labile metal fluxes for $\mathrm{Zn}, \mathrm{Cu}, \mathrm{Pb}, \mathrm{Ni}$ and $\mathrm{Cd}$. Each raincloud

245 plot combines a probability density function of metal fluxes, a boxplot providing statistical 246 inferences, and scattered data points of normalized metal fluxes. 

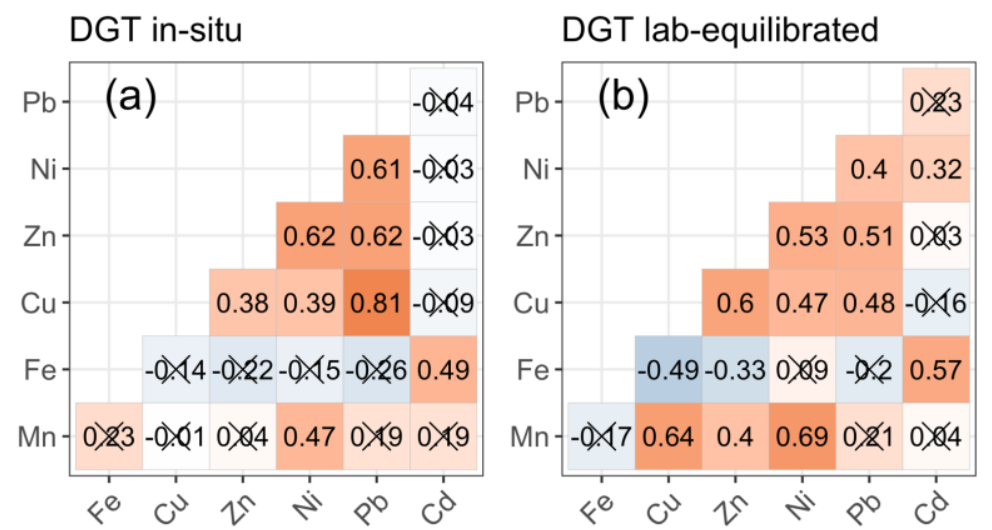

\section{DGT lab-homogenized}

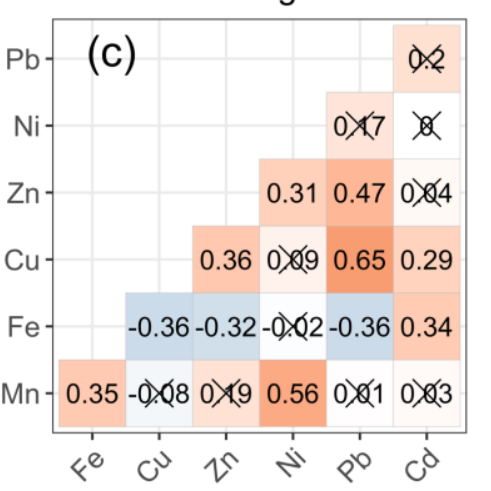

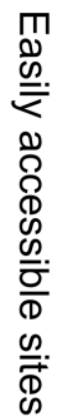

DGT lab-equilibrated

\section{DGT lab-homogenized}
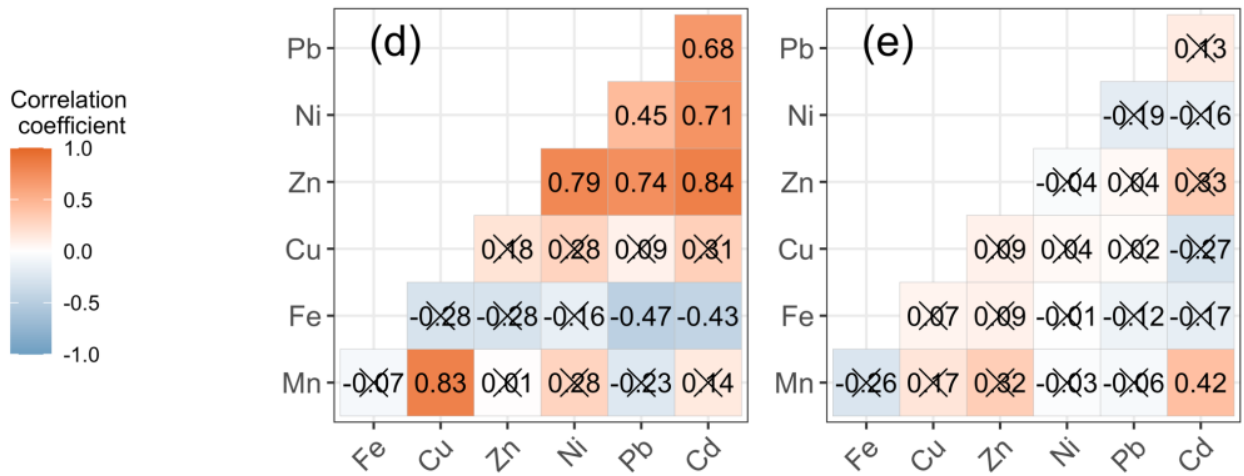

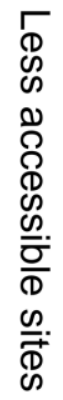

249 Figure S5. Pairwise correlations between DGT-metal fluxes for different metals under different

250 deployment scenarios. The numbers in each cell represent the Pearson correlation coefficient

251 between each pair. Crossed-off cell indicates the correlation between the metal-pair fails to pass the statistical significance test $(p>0.05)$. 
वे

253

254 Figure S6. Correlation between predicted and observed amphipod reproduction. Dashed lines

255 represent a $\mathrm{y}=\mathrm{x}$ relationship; $\mathrm{r}$ values are Pearson correlation coefficients; the asterisk symbols

256 indicate significance of correlation $(* * \mathrm{p}<0.01, * \mathrm{p}<0.05)$. 

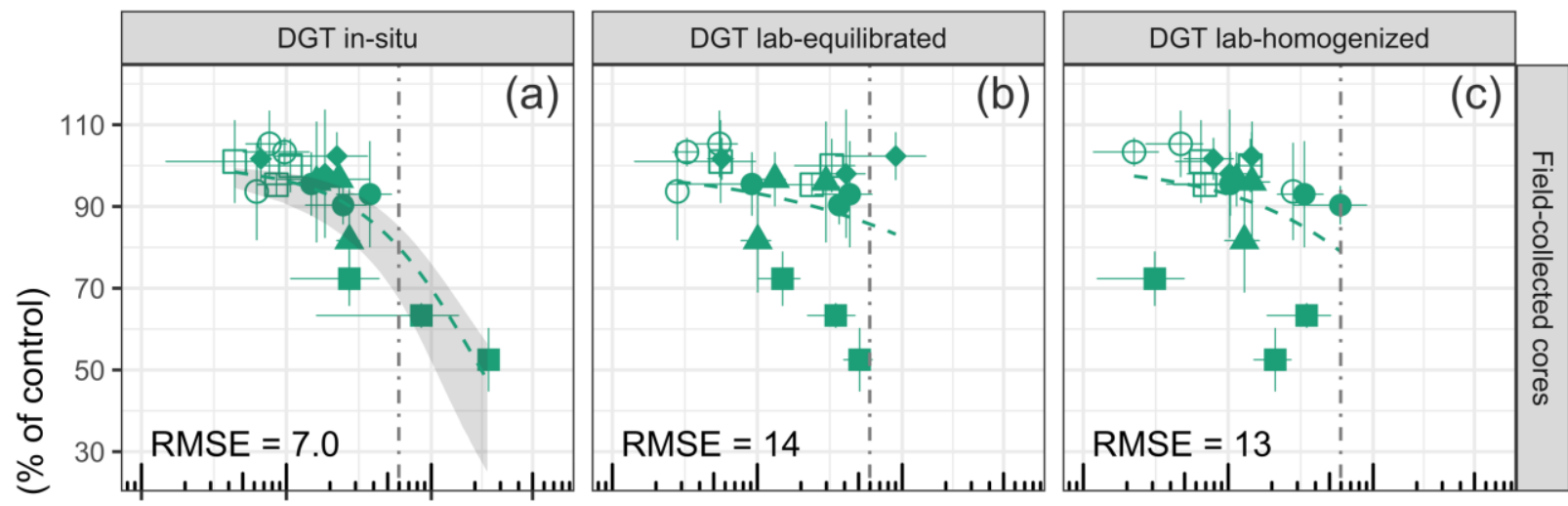

드을 음
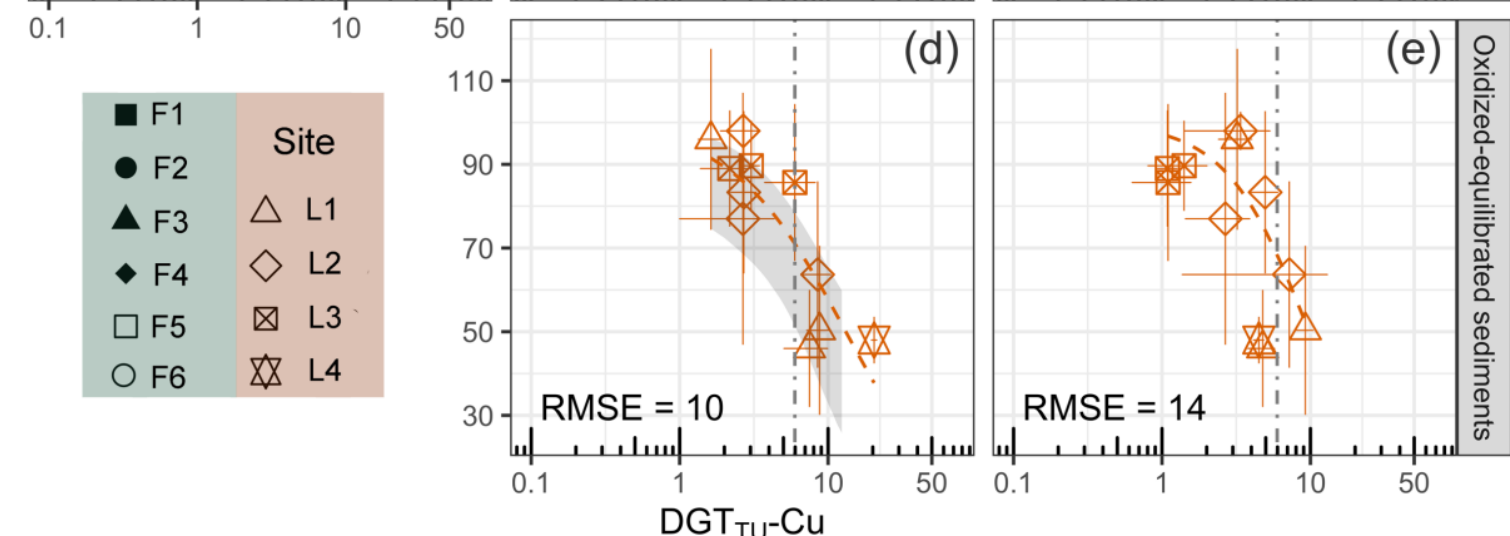
F1
Site
$\triangle \mathrm{F3} \triangle \mathrm{L}$ 1
$\rightarrow \mathrm{F} 4 \diamond \mathrm{L} 2$
$\square \mathrm{F5} \quad \triangle \mathrm{L} 3$
OF6 \& L4

Figure S7. Relationships between DGTTU-Cu and toxicity. Vertical dot-dash lines indicated EC20 derived from the DGTTU-toxicity relationship using data in panel (a). 


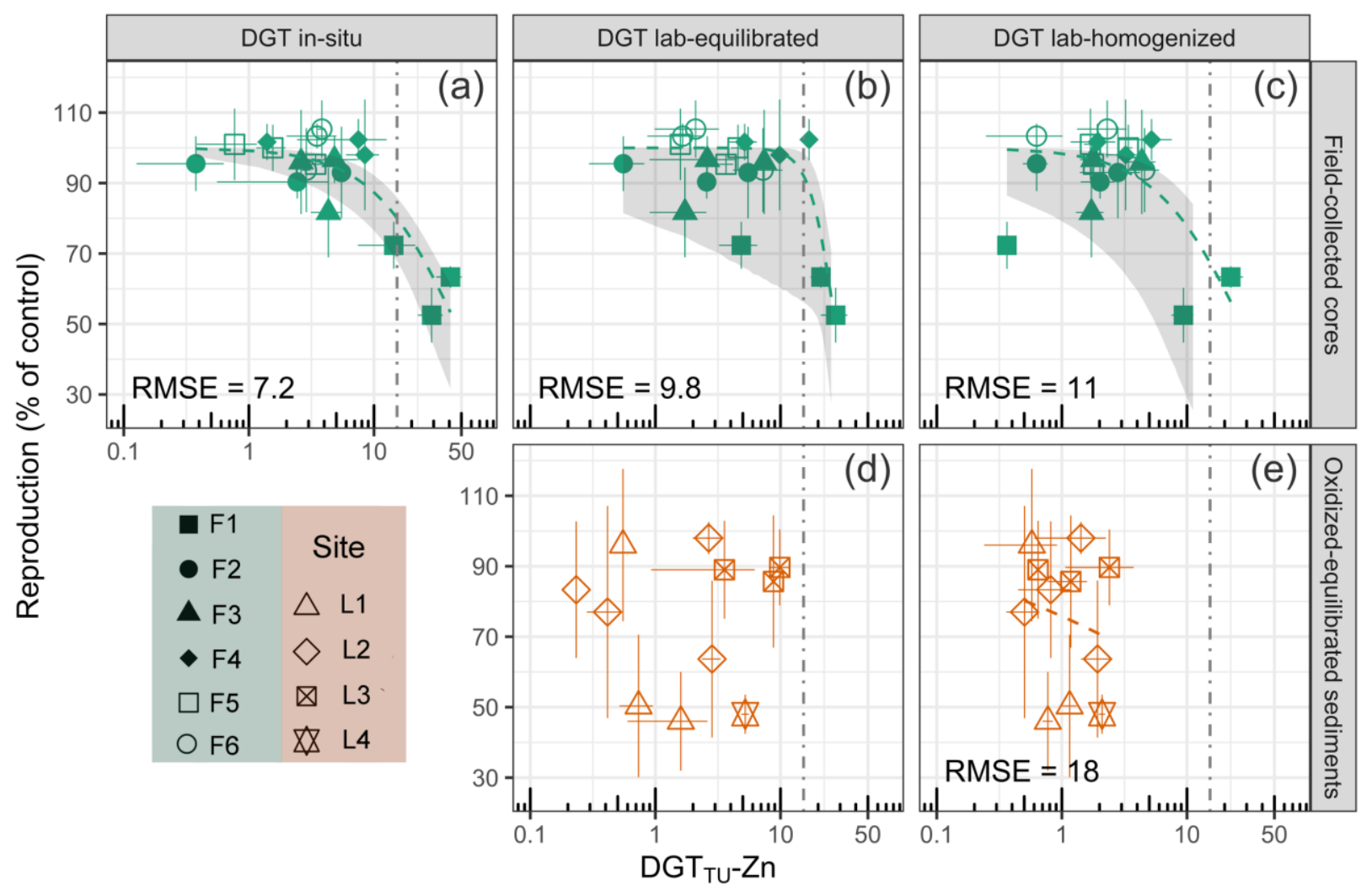

Figure S8. Relationships between DGT $\mathrm{TU}-\mathrm{Zn}$ and toxicity. Vertical dot-dash lines indicated EC20 derived from the DGTTU-toxicity relationship using data in panel (a). 


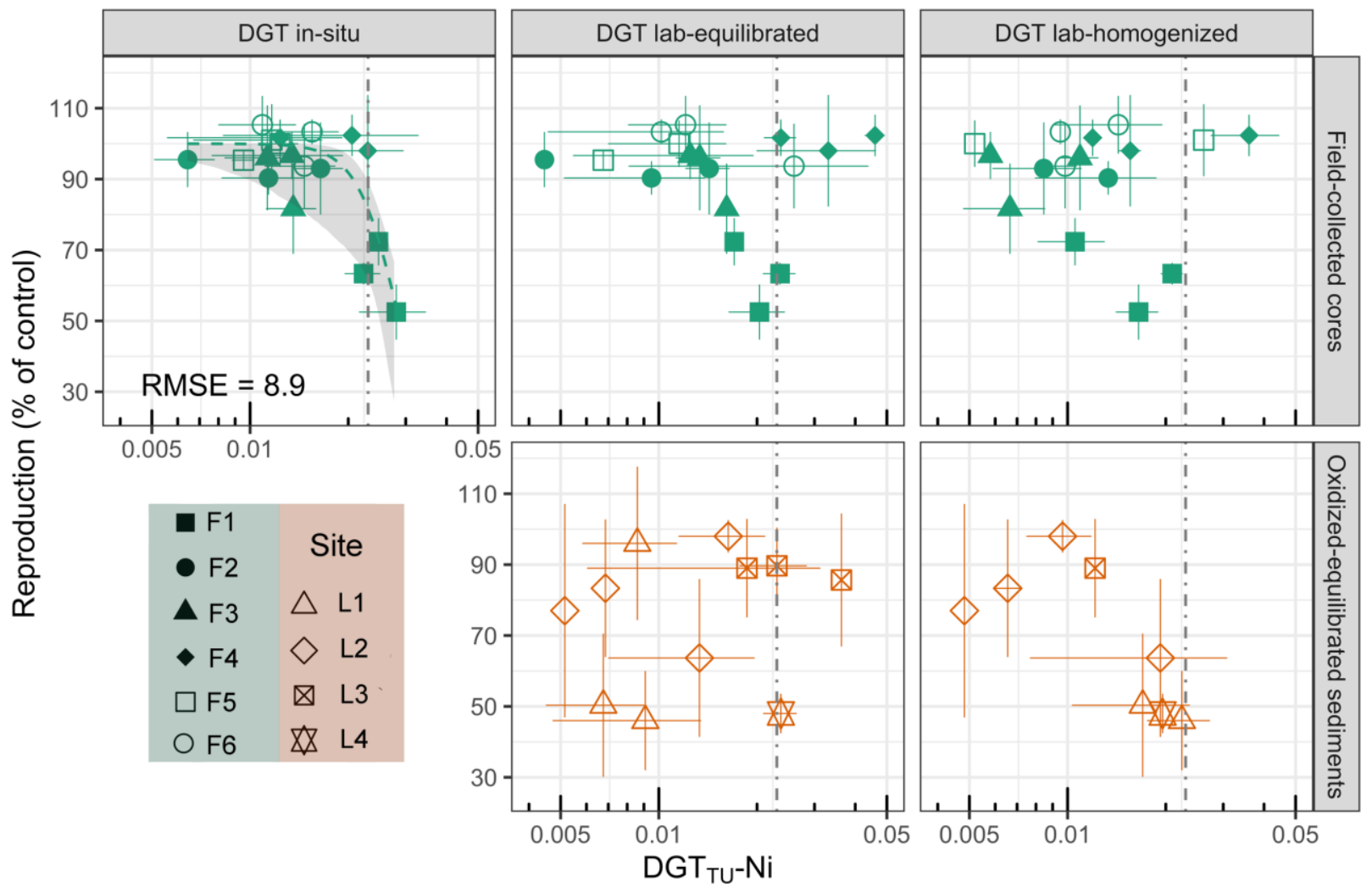

Figure S9. Relationships between DGT $\mathrm{TU}_{\mathrm{TU}} \mathrm{Ni}$ and toxicity. Vertical dot-dash lines indicated 273 EC20 derived from the DGTTU-toxicity relationship using data in panel (a). 


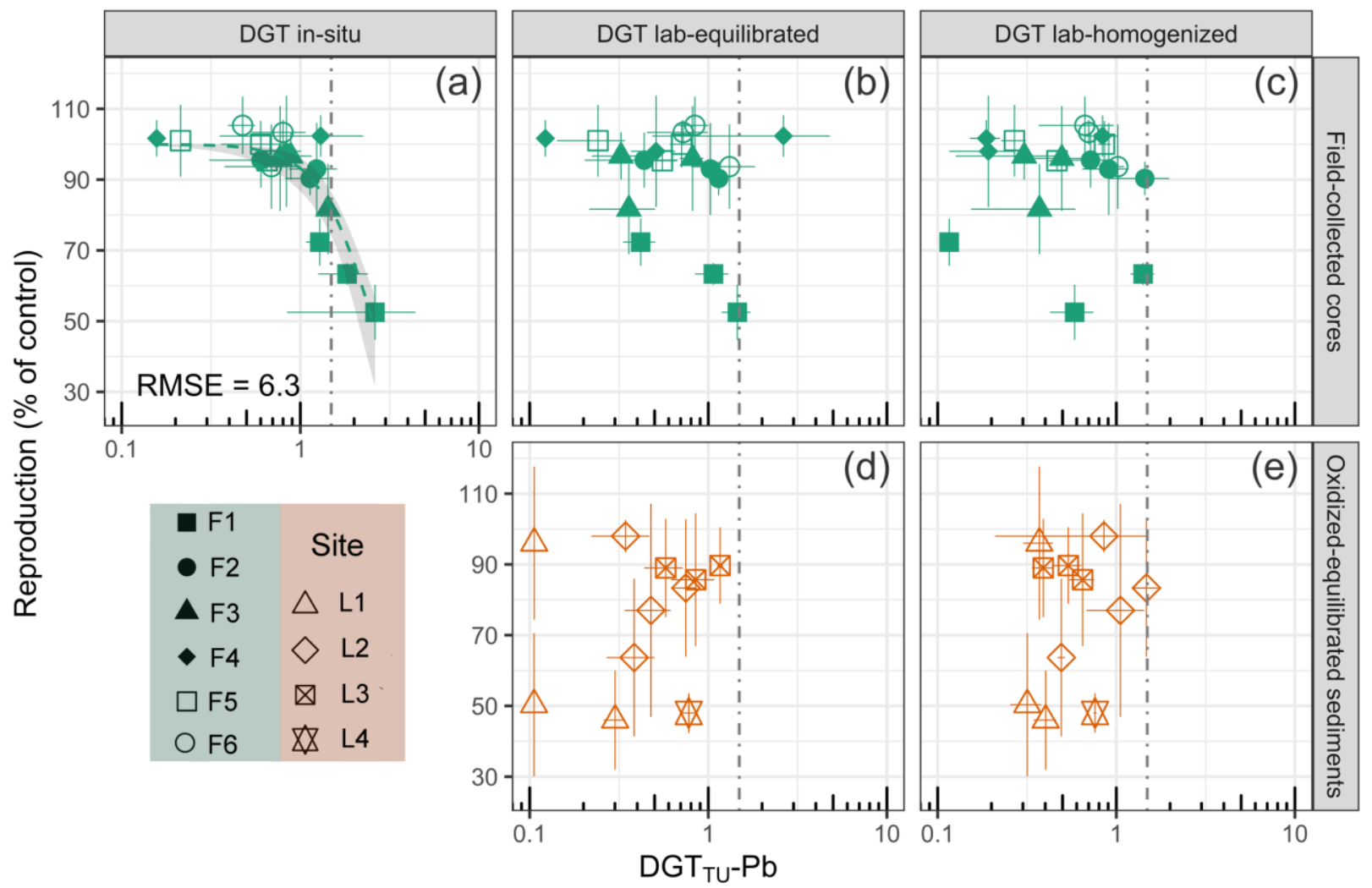

Figure $\mathrm{S} 10$. Relationships between $\mathrm{DGT}_{\mathrm{TU}} \mathrm{Pb}$ and toxicity. Vertical dot-dash lines indicated 278 EC20 derived from the DGTTU-toxicity relationship using data in panel (a). 


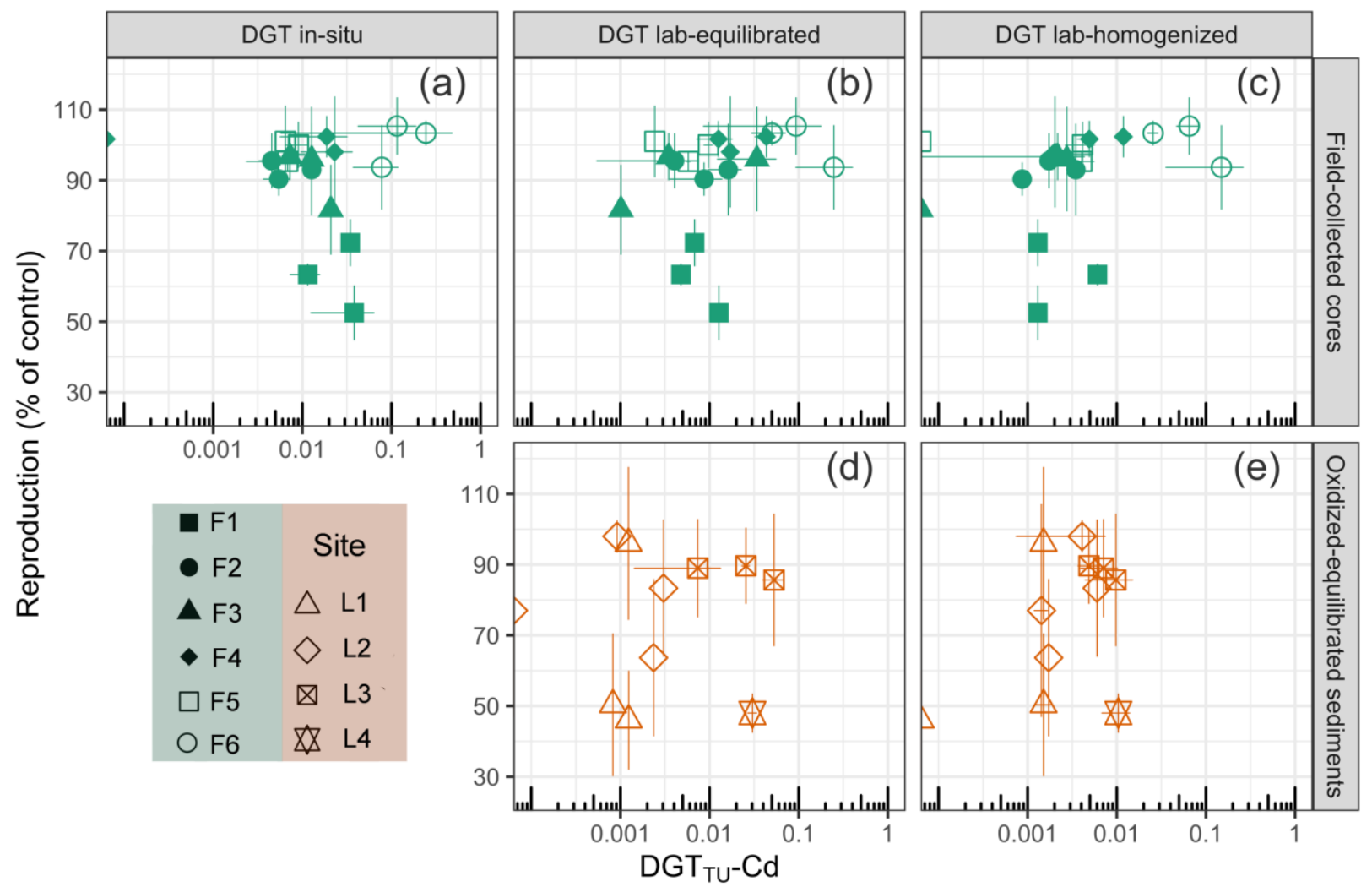

282 Figure S11. Relationships between DGT TU-Cd and toxicity. 


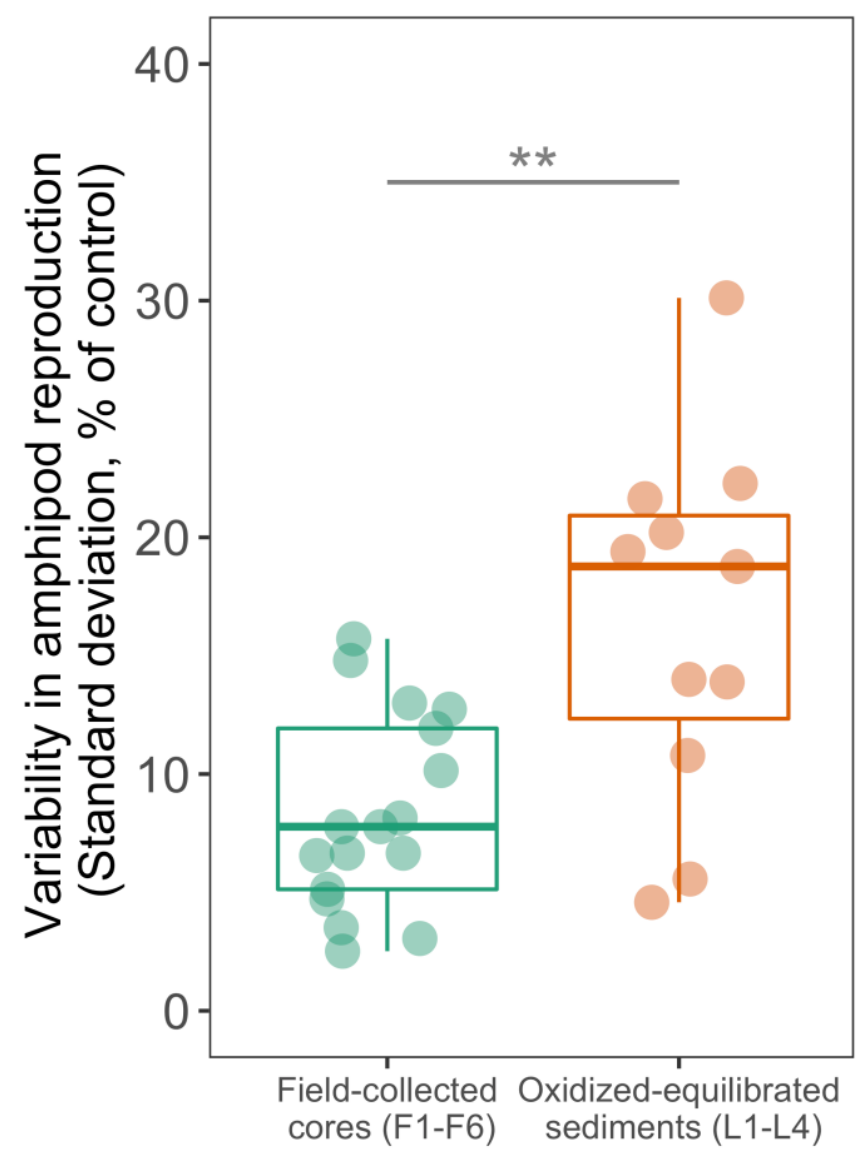

285 Figure S12. Laboratory oxidized and equilibrated sediments (highly disturbed) showed higher 286 toxicity variability than the field collected (relatively undisturbed) sediment cores (Welch's t287 test, $\mathrm{p}<0.01$ ). Distribution of standard deviations (SD) in the two group of sediments were 288 normal (shapiro.test, $\mathrm{p}>0.05$ ), but their variance was non-homogeneous (Bartlett test, $\mathrm{p}<$ $2890.05)$. 

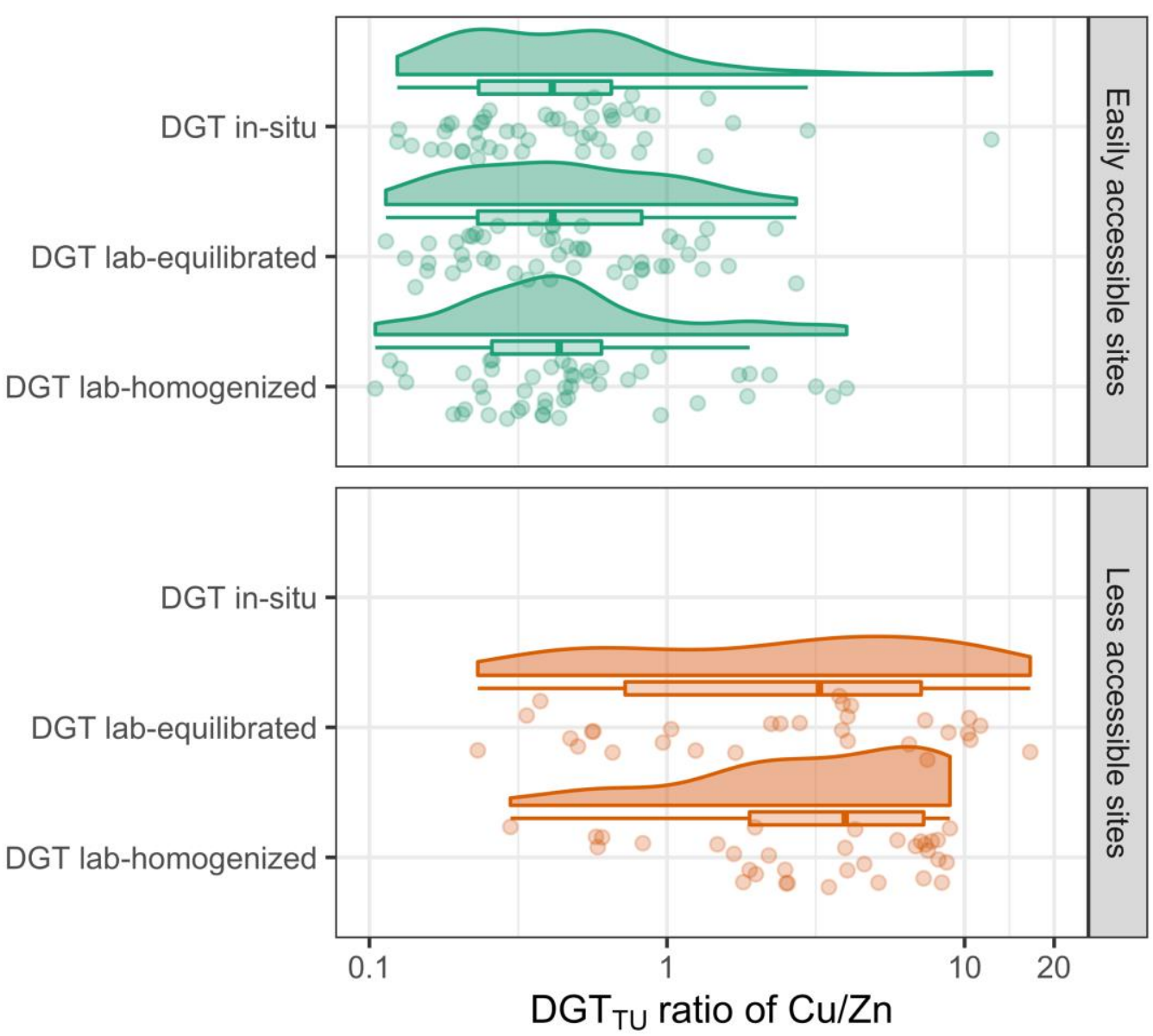

291

292 Figure S13. Ratio of DGT $\mathrm{TU}-\mathrm{Cu}$ to DGTTU-Zn.

293

294

295

296

297

298

299

300 
Reference:

302 1. Spadaro, D. A.; Simpson, S. L., Appendix E: Protocol for 10-day whole-sediment 303 sub-lethal (reproduction) and acute toxicity tests using the epibenthic amphipod Melita 304 plumulosa. In Sediment Quality Assessment: A Practical Guide, 2016; p 265.

305 2. Amato, E. D.; Simpson, S. L.; Jarolimek, C. V.; Jolley, D. F., Diffusive gradients in 306 thin films technique provide robust prediction of metal bioavailability and toxicity in 307 estuarine sediments. Environmental Science \& Technology 2014, 48, (8), 4485-4494.

308 3. Zhang, Y.; Spadaro, D. A.; King, J. J.; Simpson, S. L., Improved prediction of 309 sediment toxicity using a combination of sediment and overlying water contaminant 310 exposures. Environmental Pollution 2020, 266, 115187.

311 4. Simpson, S.; Batley, G., Sediment quality assessment: a practical guide. CSIRO 312 Publishing: Collingwood, Vic, Australia, 2016.

313 5. Simpson, S. L., A rapid screening method for acid-volatile sulfide in sediments. 314 Environmental Toxicology and Chemistry 2001, 20, (12), 2657-2661.

315 6. Remaili, T. M.; Simpson, S. L.; Amato, E. D.; Spadaro, D. A.; Jarolimek, C. V.; 316 Jolley, D. F., The impact of sediment bioturbation by secondary organisms on metal 317 bioavailability, bioaccumulation and toxicity to target organisms in benthic bioassays: 318 implications for sediment quality assessment. Environmental Pollution 2016, 208, 590-599.

319 7. Remaili, T. M.; Simpson, S. L.; Jolley, D. F., Effects of enhanced bioturbation 320 intensities on the toxicity assessment of legacy-contaminated sediments. Environmental 321 Pollution 2017, 226, 335-345. 